\title{
OLEO ORLOV:
} MEDIGINE AT THE SERVIGE : OF.SPACE DREAM 


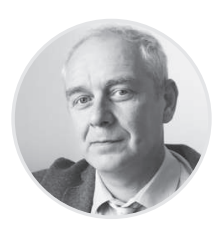

Kirill V. PLETNER,

editor-in-chief, Aerospace Sphere Journal, Moscow, Russia,

gersch@yandex.ru

Кирилл Валерьевич ПЛЕТНЕР, главный редактор журнала «Воздушно-космическая сфера», Москва, Россия, gersch@yandex.ru

ABSTRACT I Space exploration from the first steps was associated with medicine. A person's stay in conditions that were not designed for him caused a number of fundamental questions, primarily of a biomedical nature. Each of them is a real challenge for scientists. Over time, it became possible to answer them. Moreover, some studies aimed at ensuring the life and health of astronauts proved to be valuable for the treatment of terrestrial diseases. The Institute of Biomedical Problems was created in 1963 at the initiative of M.V. Keldysh and S.P. Korolev in order to conduct such studies. The editor-inchief of the journal talked with the director of the institute, academician of the Russian Academy of Sciences Oleg Igorevich Orlov, about the ways of space medicine, as well as about the unique orbital experiments and Russian scientists' bold plans.

Keywords: space medicine, Institute of Biomedical Problems of the Russian Academy of Sciences, space radiation, artificial gravity, Earth's magnetic field, hibernation, cyborgization, human birth in space
АНнотАция I Освоение космоса с первых шагов было связано с медициной. Пребывание человека в условиях, на него не рассчитанных, вызвало ряд фундаментальных вопросов, в первую очередь медико-биологического характера. Каждый из них настоящий вызов для ученых. Со временем появилась возможность ответить на них. Более того - некоторые исследования, направленные на обеспечение жизни и здоровья космонавтов, оказались ценными для лечения земных болезней. Институт медико-биологических проблем был создан в 1963 году по инициативе М.В.Келдыша и С. П. Королёва с целью проведения таких исследований. О путях космической медицины, об уникальных орбитальных экспериментах и смелых планах отечественных ученых главный редактор журнала побеседовал с директором института академиком РАН Олегом Игоревичем Орловым.

Ключевые слова: космическая медицина, Институт медико-биологических проблем РАН, космическая радиация, искусственная гравитация, магнитное поле Земли, гибернация, киборгизация, рождение человека в космосе

\section{Редакция журнала поздравяяет Олега Игоревцча Орпова с юбилеем - 2 июяя ученому исполняется $6 о$ иет. Желаем здоровья, долгих иет жизни, новых открытий и исполнения всех желаний - космических и земных!}

\begin{abstract}
- Одна из важнейших задач дяя освоения космоса - это создание искусственной гравитащии. С этой целью была разработана центрифуга короткого радиуса действия. Ее собирались установить на орбитальной станщии "Мир» еще в 80-х годах прошио20 века, сегодня 2020 год. Почему такая задержка? От чего ияи от кого зависит решение этой задачи? Когда на МКС заработает модуль с центрифугой короткого радиуса действия?
\end{abstract}

- Поскольку невесомость - один из ведущих факторов космического полета, оказывающих влияние на организм человека, считается, что создание на борту космических станций искусственной гравитации станет главным, решающим элементом в системе профилактики. В 6о-8о-х годах прошлого века активно проводились исследования адаптации человека к длительному пребыванию во вращающихся системах, для чего использовались различные стенды, например «медленно вращающаяся комната». Однако создание вращающихся космических систем - техническая задача далекого будущего. На обозримую перспективу центрифуга короткого радиуса остается единственным стендом, позволяющим воссоздавать действие гравитации на организм. Эффективность искусственной гравитации была доказана в ИМБП в 1970-х годах — как в наземных модельных исследованиях, так в полетах по программе «Бион». Надо отметить, что исследования в этом направлении шли очень активно. Полученные еще в те годы данные легли в основу нового перспективного метода лечения - гравитационной терапии, которая в наши дни находит широкое применение. 
Однако затем исследования были приостановлены. Возобладала точка зрения, что созданная к тому времени система профилактики достаточно эффективна для обеспечения орбитальных полетов и, соответственно, создание искусственной гравитации избыточно. Второе дыхание проблема искусственной гравитации получила с началом обсуждения в практическом плане межпланетных пилотируемых программ. Сейчас этим активно занимаются во многих космических центрах - в США, Европе, Китае, Японии. Вернулись к этому вопросу и в ИМБП. В настоящее время наши исследования направлены на создание методики наиболее эффективного применения вращения на центрифуге короткого радиуса в составе комплекса средств профилактики. Серьезная задача - создание стенда для размещения на борту космической станции. Подготовительные расчеты обоснования такой конструкции раньше предпринимались для МКС кооперацией участников американского сегмента, но были приостановлены из-за высоких рисков динамического воздействия стенда на всю станцию. Мы подготовили обоснование создания бортовой центрифуги в составе трансформируемого модуля, разрабатываемого НПО «Энергия». Это предложение утверждено. Модуль должен стать составным элементом Российской орбитальной станции. Дело за малым - принять стратегическое решение о создании станции и начать опытно-конструкторские работы.

- Вmорой главный вопрос: воздействие радиации и других вредных космических изпучений на космонавта во время дапьних космических полетов. Какие решения дия защиты космонавта во время межпланетного полета может предложить ИМБП?

- Вызывает беспокойство даже не столько собственно уровень радиации, сколько наличие в составе космического излучения ядер тяжелых ионов, которые, "пролетая» через организм, могут вызвать необратимые последствия. Это повышает риски для межпланетной экспедиции, а если говорить о длительном пребывании в дальнем космосе - может привести, в частности, к накоплению повреждений молекулярной структуры ДНК, со всеми вытекающими последствиями - от онкологических заболеваний до наследственных нарушений. Как с этим быть?

В первую очередь, отбирать космонавтов, наименее подверженных воздействию радиации. В наших экспериментах с приматами доказано, что степень нарушения когнитивных функций после облучения ядрами углерода меньше у животных с более подвижным типом мозговых

Демонстрация стенда ПТК «Федерация» во время визита директора ИМБП РАН и членов экипажа эксперимента «Луна-2015» в РКК «Энергия» (фото из архива ИмБП)

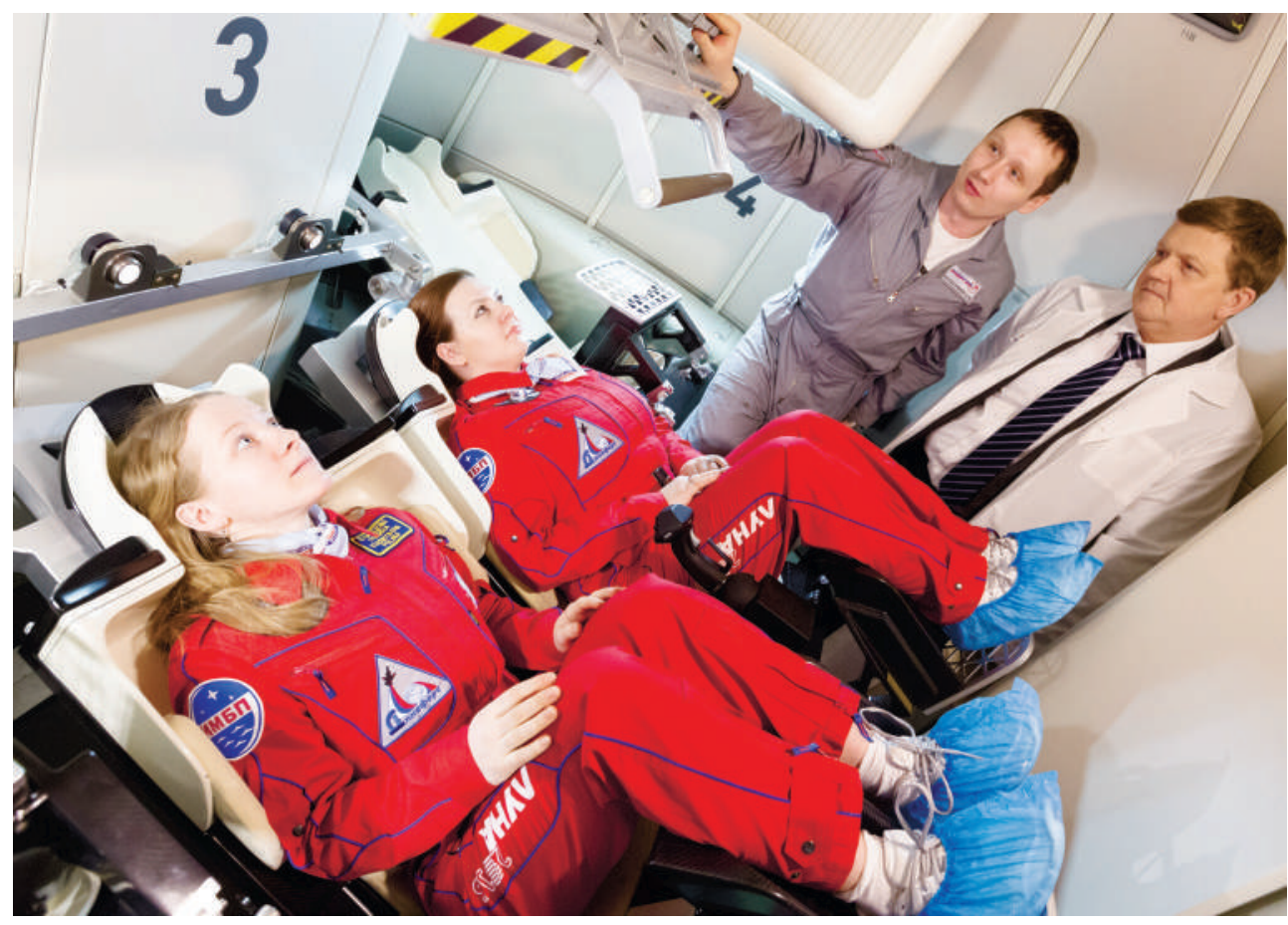




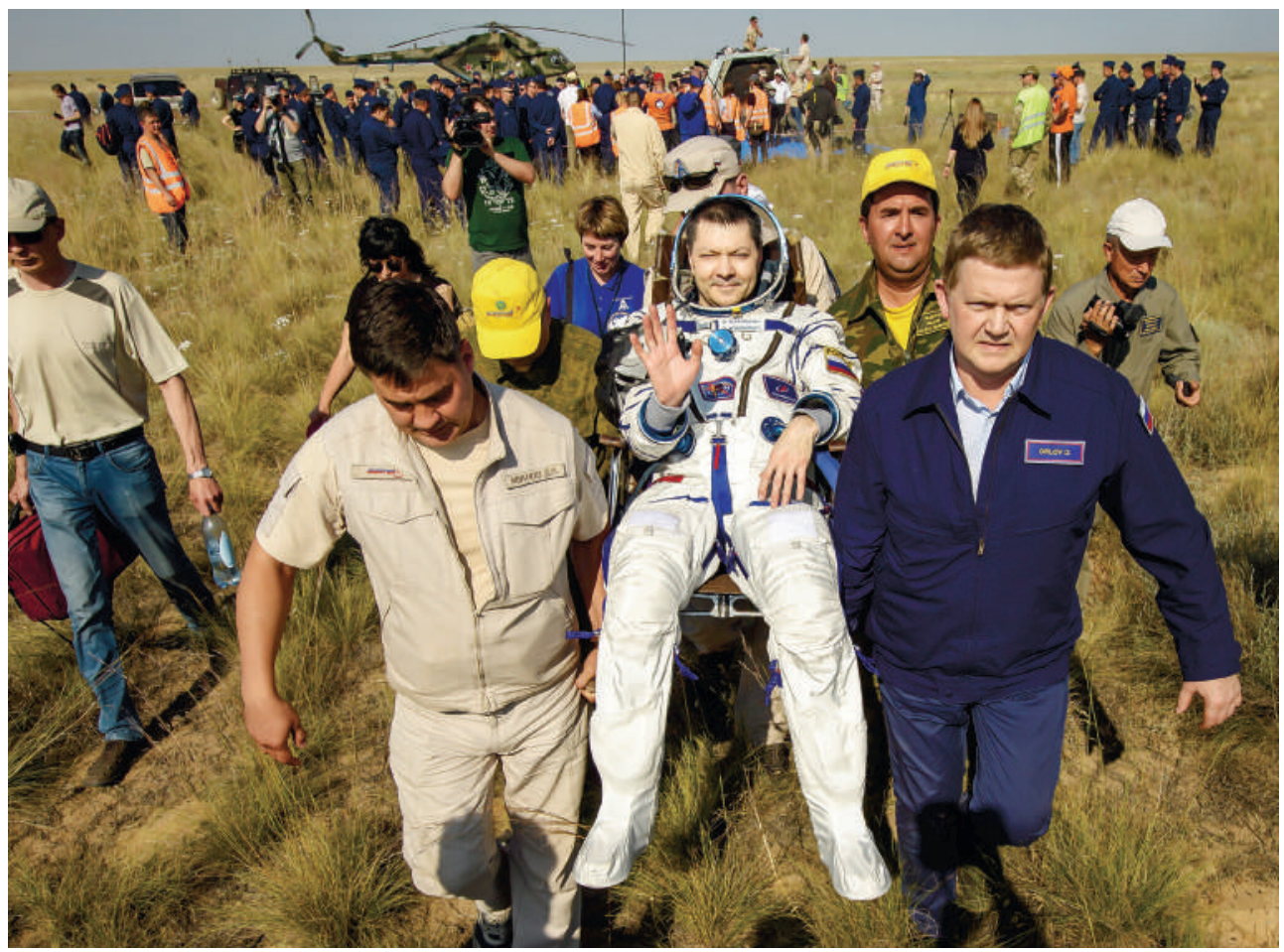

На месте посадки КК «Союз МС-11» (59-я экспедиция МКС). Летчика-космонавта Олега Кононенко переносят в медицинскую палатку, 2019 год (фото из архива НАСА)

функций. Но мы пока только в начале пути. Еще один связанный с индивидуальными реакциями вопрос - пластичность мозга, возможность компенсировать функции поврежденных клеток. В процессе полета можно думать о профилактике, например фармакологической, и, в первую очередь, о защите корабля. Бесконечно утолщать стенки не получится. Во-первых, можно получить неподъемную для выведения крепость, во-вторых, при определенной толщине стенки сами могут стать источником вторичного излучения. Можно предусмотреть радиационные убежища на случай возникновения ограниченных по времени ухудшений радиационной обстановки, например так называемых солнечных событий. Или предложить индивидуальные носимые средства защиты, есть у наших сотрудников и такая разработка. Но находиться в ней долго вряд ли получится. Можно повысить безопасность мест длительного пребывания, спальных в частности. Кстати, мы с успехом занимаемся этим на MKC. Наши специалисты предполагают, что эффективным может оказаться создание вокруг корабля искусственного магнитного поля, которое будет еще и компенсировать отсутствие естественного фактора. Обоснование этого предложения еще предстоит уточнять, кроме того, возникают технические вопросы реализации и энергопотребления такой установки.
- Есть точка зрения, что опсутствие магнитно20 поля Земии дия человека настолько губительно, что межпианетные путешествия невозможны. Насколько изучен этот вопрос?

-У людей, в силу профессии длительное время находящихся в условиях сниженного в 2-10 раз естественного магнитного поля, могут возникать различные нарушения со стороны сердечно-сосудистой, иммунной, нервной и других систем. Поэтому время пребывания в таких условиях для них ограничено требованиями санитарно-эпидемиологических правил и нормативов.

В межпланетном пространстве поле снижено до 10000 раз. Мы знаем, что в таких условиях у биологических объектов нарушаются процессы онтогенеза, наблюдаются изменения во внутренних органах. Есть наблюдения, когда подопытные животные утрачивали навыки социального поведения, испытывали проблемы с памятью. Но все это - исследования на биологических моделях. В наших экспериментах с участием человека длительностью несколько часов мы не обнаружили каких-либо драматических изменений состояния основных функциональных систем, что, в общем-то, вполне ожидаемо. Необходимы дальнейшие исследования большей продолжительности, как с участием человека, желательно экипажа, 
так и эксперименты на биологических моделях. Причем надо иметь в виду, что гипомагнитная среда может воздействовать на любые биологические объекты, в том числе входящие в состав системы жизнеобеспечения.

- Какие задачи кроме искусственной гравитации, воздействия радиации и гипомагнитной среды с медицинской точки зрения необходимо реиить для обеспечения постоянного пребывания в космосе на тех же допговременных пунных базах?

- Сегодня не рассматривается сценарий постоянного пребывания на долговременных лунных базах. Скорее, речь идет о посещаемых лунных станциях, работающих в основное время в автоматическом режиме. Но Луна - это промежуточная ступень к полетам в дальний космос и освоению пространства вне орбиты Земли. В связи с этим я бы предложил остановиться на двух важных аспектах, которые тем не менее не исчерпывают список.

Итак, первая проблема - создание системы жизнеобеспечения. На орбите она строится на принципе восполнения запасов, доставляемых с Земли. Межпланетную экспедицию на таких принципах не построишь. Конечно, можно взять определенное количество запасов с собой, можно предварительно выслать на орбиту Марса, например, грузовые корабли для доснабжения экспедиции. Но очевидно, что нужны системы, самовоспроизводящие основные элементы - биологические системы жизнеобеспечения. Это одинаково важно как для дальних межпланетных полетов, так и для внеземных поселений. Работы в этом направлении активно велись в СССР, в том числе в ИМБП. К сожалению, тематика оказалась заброшена, а ее опытом успешно воспользовались наши зарубежные партнеры.

Вторая задача - собственно разработка системы медицинского обеспечения. Существующая отечественная система доказала свою эффективность при полетах различной продолжительности, в том числе сопоставимых по длительности с межпланетными. Но это - на орбите. Все построено на поддержке наземных служб и возможности возвращения экипажа при возникновении внештатной ситуации. В условиях межпланетного полета или напланетной базы это исключено. Соответственно, система должна функционировать автономно при поддержке мощного информационного комплекса (мы называем его "интеллектуальный телемедицинский контур») и содержать большое количество инструментария и методик, которые еще предстоит разработать.

- А может быть, оставить космонавта в покое и дамь организму возможность адаптироваться к условиям космоса самостоятельно? Отобрать наиболее генетически приспособленных к этому июдей ияи целенаправленно сформировать такие свойства у будущих космонавтов методами генной инженерии?

- Может, и можно было бы оставить космонавта в покое, если бы у него не возникала необходимость возвращаться на Землю или работать на поверхности планет с тем или иным уровнем гравитации. На самом деле мы не знаем, как далеко могут зайти процессы, которые сегодня описаны как эффекты влияния факторов космического полета на организм человека при условии полного отказа от какой-либо профилактики. Наступят ли необратимые изменения, несовместимые с существованием нас как представителей гравитационно-зависимого биологического вида? Или человек адаптируется к новым условиям существования и приведет свои физиологические системы к другому уровню функционирования, востребованному в этих новых условиях?

Система профилактики в настоящее время тоже построена на необходимости поддержания готовности экипажа к внештатной посадке. В межпланетном полете такой задачи, вероятно - к сожалению - нет. Мы должны научиться управлять состоянием человека, чтобы он был достаточно адаптирован к длительному пребыванию в невесомости, мог выполнять внекорабельную деятельность и готовиться к работе на поверхности планет с различным уровнем гравитации, а в какой-то момент начать подготовку к возвращению на Землю. Это должно быть более рационально, чем изо всех сил стараться удержать космонавта на уровне земной тренированности в течение всей межпланетной экспедиции.

«В настоящее время никаких определенных научных данных для генетического отбора в профессию космонавта нет, хотя продолжать заниматься этим направлением надо. Что касается целенаправленного воздействия на генетический апnарат - это задача, созвучная стремлению создать идеального солдата».

Перспектива отбора космонавтов по генетическим признакам давно волнует ученых. Когда я проходил отбор в отряд космонавтов, на заключительном этапе в клинике появились генетики - представители одной из смежных организаций, которые пытались с помощью линейки выяснить нашу генетическую пред- 
Олег Иеоревич் Орлов - специазиологии и медицины, гравитационной биологии, телемедицины, автор более 190 научных работ.

Поступил в аспирантуру при ИМБП в 1984 году после окончания Московской медицинской академии имени И.М.Сеченова по специальности «лечебное делі», где занимался исследовательской работой в области регуляции водно-солевого обмена в условиях гипербарии, а затем применительно к моделированию факторов космического полета.

Олег Орлов провел разностороннее изучение механизмов влияния гипокинезии и гиподинамии на обмен кальция, системы его регуляции и состояние костной ткани. В серии экспериментов с крысами им показаны различные эфффекты данных моделей на прочностные характеристики, морфометрические показатели и минеральный состав костной ткани, а также обосновано применение формакологических менений.

В 1987 году защитил кандидатскую диссертацию «Влияние дифосфонатов на обмен кальция, его регуляцию и состояние костной ткани при моделировании физиологических эффектов невесомости». По окончании аспирантуры работал на научных должностях в отделе фбизиологйи ускорений. лист в области космической фбисредств коррекции наблюдаемых из-

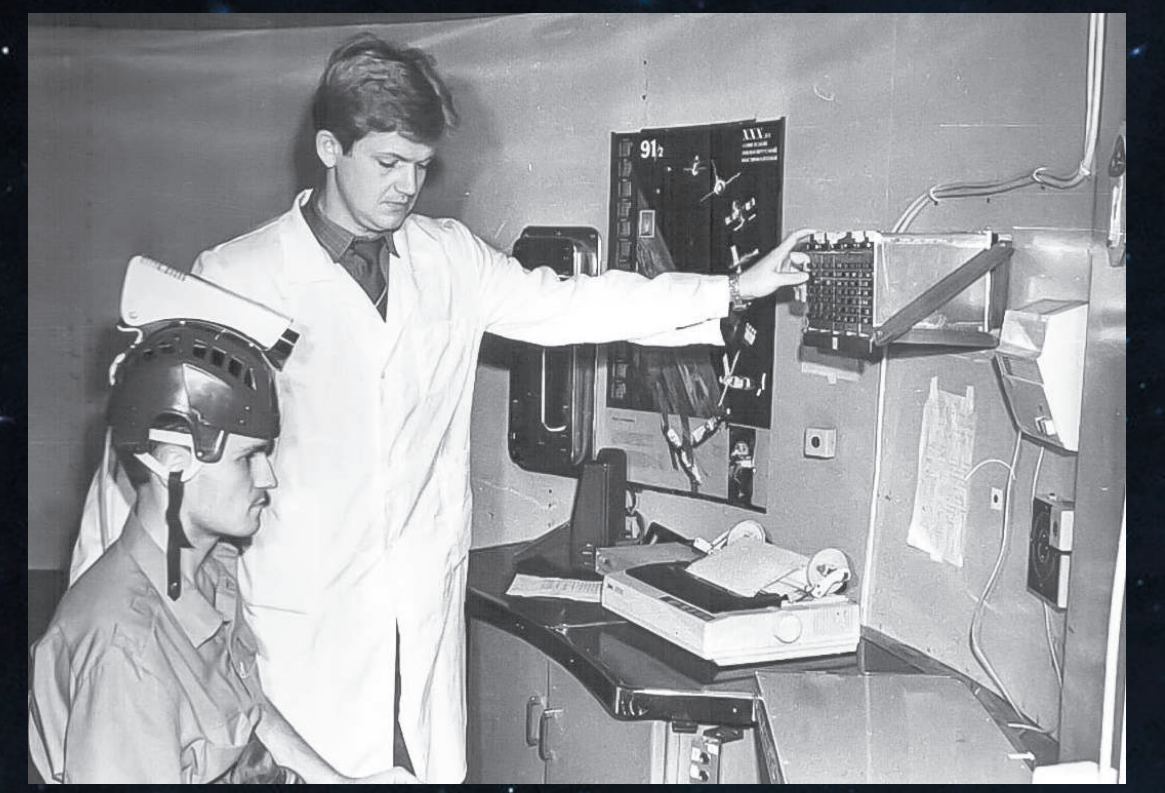

Обследование участников эксперимент́а «Юпитер-2» (фото из архива ИМБП)

Принимал участие в экспертной работе по отбору и освидетельствованию космонавтов, а также в исследованиях по изучению устойчивости организма к перегрузкам.

о.И. Орлов провел систематическое изучение фоизилогических реакций организма при длительном пребывании в условиях медленно вращающейся среды, что позволило оценить эgфбективность различных средств проgолактики болезни движения применительно к начальным этапам космического полета.

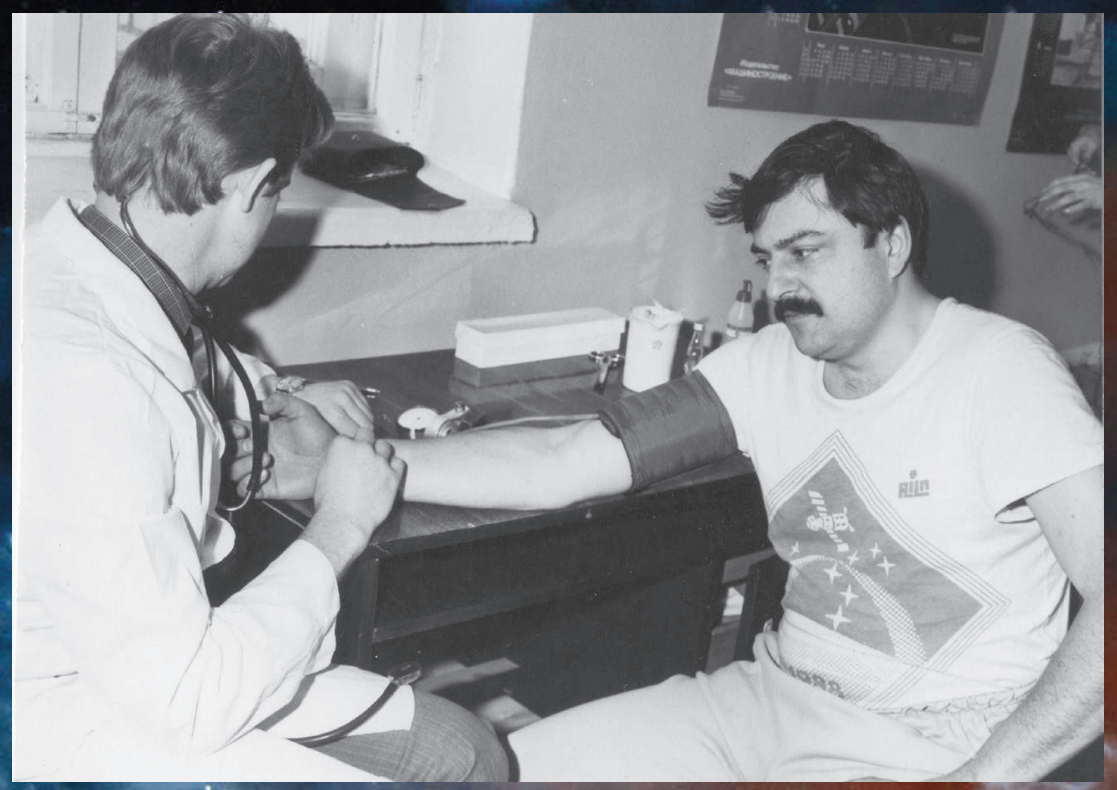

о.И. Орлов пров̀оит медицинское освидетельствование летчикакосмонавта Мусы Манарова, 1988 год (фото из архива ИМБП)
Апробированные и целенаправленно отобранные в ходе исследований комплексные ' фармакологическuе средства на основе скополаминсодержащих препаратов были в дальнейшем эфбфективно использованы в условиях космического полета.

О.И. Орловым впервые, на основании использования разработанной оригинальной модели, доказано, что космическая форма болезни движения приводит к снижению переносимости перегрузок $+\mathrm{Gz}$, появлению при их воздействии симптомов укачивания. Это послуэило. обоснованием целесообразности специального изучения нерёносимости перегрузок на'этапе острой адаптации к состоянию невесомости и последующего перехода к условиям земной гравитации на различных стадиях развития болезни движения применительно к полетам многоразовых космических систем.

Во время работы в институте активно участвовал в исследованиях в качестве испытателя-добровольца. Прошел медицинский отбор в отряд космонавтов.

C 1997 по 2006 год являлся генеральным директором Государственного научно-учебного учреждения «Учебно-исследовательский центр космической биомедицины», созданного ИМБП и МГУ именИ М.В. Ломоносова при поддержке Министерства науки и технологий РФ и NASA. 
расположенность к космической профессии. Нас, молодых балбесов, уже ощущавших себя почти героями космоса, это страшно веселило. Если серьезно, в настоящее время никаких определенных научных данных для генетического отбора в профессию космонавта нет, хотя продолжать заниматься этим направлением надо. Что касается целенаправленного воздействия на генетический аппарат - это задача, созвучная стремлению создать идеального солдата. Научный инструментарий развивается очень быстро, часто - опережая возможность осмыслить получаемые с его помощью результаты. Повернуть "генетический винтик» уже можно, знать бы, какой именно и в какую сторону, а при этом еще и быть уверенным в полученном результате. И еще - важно осмыслить нравственно-этическую сторону вопроса.

- Одна из идей защиты человеческого организма во время длительного космического полета - это гибернация. Насколько эта идея состоятельна?

- Идея использования гибернации, а более точно - состояния анабиоза, вполне состоятельна и в далекой перспективе, вероятно, реализуема практически. Наше внимание в этом смысле привлекли состояния управляемого анабиоза, практикуемые в буддизме. Сейчас совместно с коллегами из Института мозга человека имени Н. П. Бехтеревой РАН и Бангалорского университета при поддержке Далай-ламы мы пытаемся найти подходы к изучению этого феномена с позиций современной физиологии.

- Термин «киборг», машинно-человеческий гибрид как биологический организм, содержащий механические и электронные компоненты, бып введен в связи с концепцией расширения возможностей человека дия выживания вне Земии. Что вы думаете по этомy noводy?

- Предлагаю определиться в том, что, говоря о киборгах применительно к пилотируемой космонавтике, мы имеем в виду организм с человеческим сознанием и человеческим мозгом как его носителем. Если человеческий мозг заменен машинным, пусть самым совершенным, - это уже робот.

«Говоря о киборгах применительно к пилотируемой космонавтике, мы имеем в виду организм

с человеческим сознанием и человеческим мозгом как его носителем. Если человеческий мозг заменен машинным, пусть самым совершенным, - это уәке робот».
Под «космическим киборгом», на мой взгляд, следует рассматривать весь пилотируемый межпланетный комплекс, где человек сосуществует как естественный необходимый элемент. Киборгизация человека в этом контексте - способ повышения его способности интегрироваться в систему «человек - машина», а такке придания (усиления) качеств, необходимых для успешной адаптации к условиям выполнения космической миссии. Развитие технологий приема, обработки, анализа информации и принятия решений рассмотрены нами в рамках концепции «интеллектуального телемедицинского контура». Технологии управления внешними устройствами активно изучаются в исследованиях, которые можно условно объединить в рамках тематики «мозг - компьютер интерфейс». Применение элементов киборгизации (например, имплантатов) возможно с целью защиты мозга от повреждающих факторов внешней среды, восстановления утраченных и активизации имеющихся функций. В мире ведется множество работ в области создания искусственных органов и тканей человека небиологической природы. В перспективе можно обсуждать возможность их «профилактической» пересадки на этапе подготовки к полету. Перспективным признано направление создания искусственных органов из стволовых клеток человека. Другой областью научных исследований является печатание тканей и органов (3D-биопринтинг). Первые эксперименты в космическом полете, проведенные компанией 3D Bioprinting Solutions при нашем участии, вселяют надежду на перспективность этой технологии. Отдельная научно-практическая задача - проведение в условиях полета хирургических вмешательств по пересадке органов и тканей и/или их выращивание in situ.

Самостоятельная проблема, которая тем не менее может рассматриваться как дополнительный элемент киборгизации, - применение внешних/внутренних устройств, усиливающих функции с различной степенью интеграции с организмом киборга (робототехнические элементы, экзоскелетон и т.п.).

- Что вы можете ответить на критику изоляционных экспериментов? Ряд экспертов считают, что деньги потрачены напрасно. Летчик-космонавт Валентин Лебедев заявля, ито в эксперименmе «Марс-5оо" «все условно, как если бы подготовку к дрейфу на пьдине в Арктике проводияи зимой на подмосковном пруду. А привлеченные к этому эксперименту участники могут в июбую минуту отказаться от его продолжения, выйти и обнять своих близких». И это нивелирует серьезность психическо20 испытания дяя участников. 

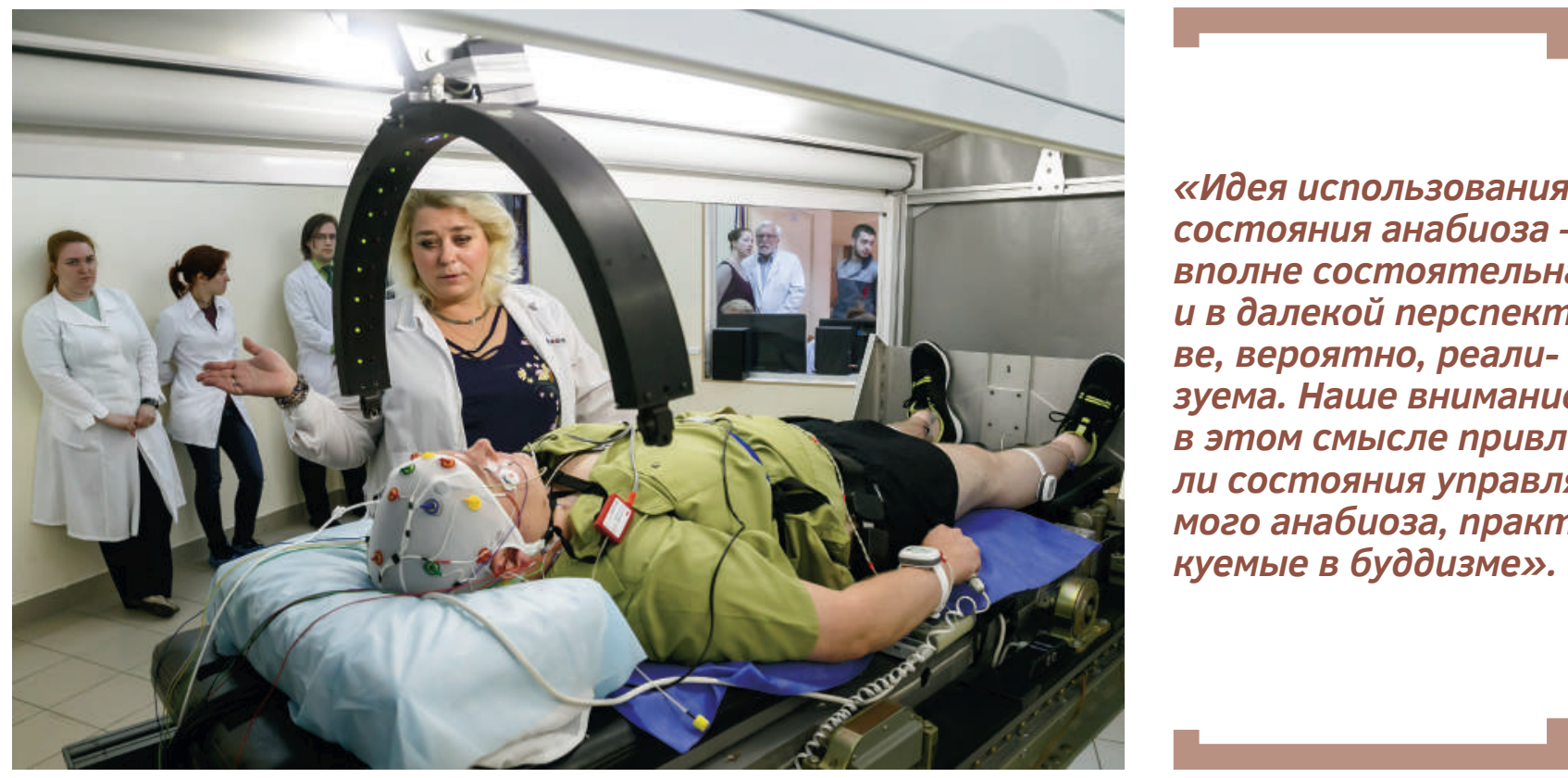

«Идея использования состояния анабиоза вполне состоятельна и в далекой перспективе, вероятно, реализуема. Наше внимание в этом смысле привлекли состояния управляемого анабиоза, практикуемые в будаизме».

Первая серия экспериментов по разработке средств профилактики и тестовых методик для оценки состояния сердечно-сосудистой, мышечной и сенсорных систем на центрифуге короткого радиуса, 2018 год (фото из архива ИМБП)

- Изоляционные эксперименты - один из способов воспроизвести отдельные факторы космического полета в наземных условиях, наряду с антиортостатической гипокинезией, иммерсией и некоторыми другими более частными моделями. Каждая такая модель имеет свои преимущества и недостатки и, соответственно, свое предназначение. Изоляционными или аналоговыми исследованиями широко пользуются ученые не только нашей страны, но и США, Китая, Европейского космического агентства. Комплекс, в котором проводятся изоляционные эксперименты в ИМБП, так называемый Наземный экспериментальный комплекс, или НЭК, - это макет тяжелого межпланетного космического корабля, созданный по замыслу еще С. П. Королёва. Пока аналогов ему в мире не существует. Космонавты, которым пришлось участвовать в изоляционных экспериментах в НЭК, отмечают, что условия жизни и работы экипажа ближе к условиям реальной экспедиции, чем это можно было предполагать. Те, кому пришлось участвовать в экспериментах на этапе подготовки к реальным полетам, отмечают, что работа в НЭК оказалась очень полезным опытом. Поэтому мы договорились с руководством ЦПК имени Ю. А. Гагарина об участии по мере возможности в наших исследованиях кандидатов в космонавты.

- ИМБП ведет изоляционные эксперименты начиная с 1968 года. Какие главные выводы и открытия этих экспериментов, каково их научное значение? Насколько они будуm способствовать межиланетным путешествиям?

- Среди исследований, проведенных в 6о-е годы $\mathrm{XX}$ века, наиболее длительным был годовой медико-технический эксперимент «Год в земном звездолете», проведенный в наземном лабораторном комплексе с тремя испытуемыми. Он проводился с ноября 1967 по ноябрь 1968 года в рамках советской марсианской программы и был направлен на изучение факторов сверхдлительного пребывания экипажа в условиях искусственной среды обитания и ограниченного объема применительно к межпланетным полетам. В результате эксперимента были получены существенные данные о влиянии на здоровье, психофизиологическое состояние и работоспособность экипажа длительного пребывания в гермообъеме с искусственной замкнутой средой обитания (сформированной в том числе с помощью оранжереи) с пониженным содержанием кислорода и повышенной концентрацией $\mathrm{CO}_{2}$. Результаты эксперимента поставили ряд психофизиологических проблем, с которыми неизбежно столкнется экипаж в длительной миссии.

После введения в эксплуатацию НЭК было проведено несколько очень важных экспериментов с изоляцией, каждый из которых имел определенную научно-практическую задачу. В частности, по соглашению с Европейским космическим агентством (ЕКА) в 1993 году, был успешно 


«Результаты экспе-
римента "ЭкопСИ-95"
достоверно подтвер-
дили, что растения
космической оранжереи
оказывают позитив-
ное влияние не только
на пищевой рацион,
но и на психологический
климат в экипаже, ком-
пенсируя недостаток
"домашнего" комфорта
на станции, а также
отсутствие компонен-
тов живой природы».

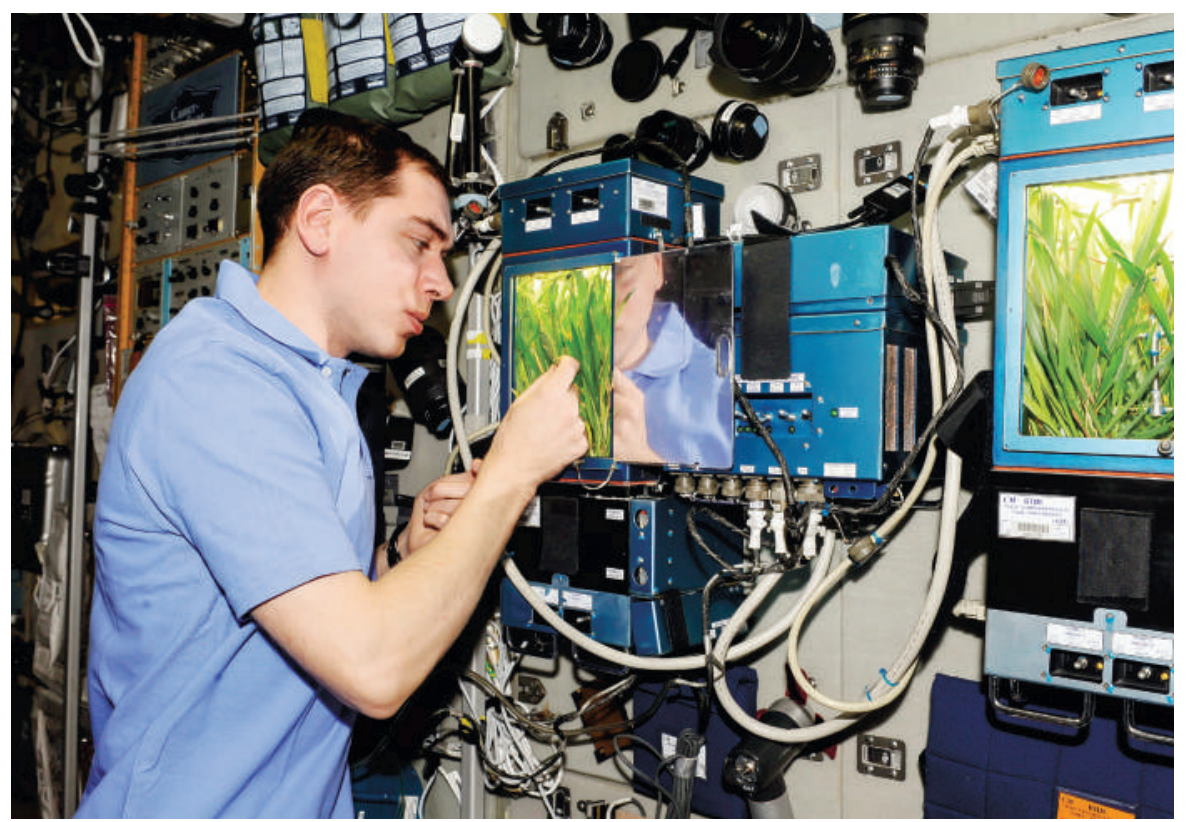

Летчик-космонавт Сергей Волков проверяет ход эксперимента «Растения-2» в оранжерее «ЛАДА-01». МКС, 29-я экспедиция, 2011 год (фото из архива HACA) проведен эксперимент HUBES-94, моделирующий ряд условий и научную медико-психологическую программу запланированного 135-суточного полета европейского космонавта на борту орбитальной станции «Мир» (программa EUROMIR-95). Результаты эксперимента “ЭКОПСИ-95" (октябрь 1995 года - январь 1996 года) достоверно, с помощью современных научных методов, подтвердили, что растения космической оранжереи оказывают позитивное влияние не только на пищевой рацион, но и на психологический климат в экипаже, компенсируя недостаток "домашнего» комфорта на станции, а также отсутствие компонентов живой природы. Основной целью эксперимента SCFINCSS-99 было получение экспериментальных данных о влиянии длительной изоляции в герметичном замкнутом пространстве на взаимодействие в международных экипажах с неоднородным национальным составом. Эксперимент моделировал условия полета на готовящейся к эксплуатации МКС. В проведении эксперимента приняли участие ученые из девяти стран. Конечно, самым крупным международным проектом по изоляции стала серия экспериментов "Марс-50о» (2007-2011 годы), получившая широкое международное признание и «Лавровую ветвы» Международной академии астронавтики как выдающееся достижение международной группы ученых и специалистов. В рамках проекта "Марс-5оо» экипажи выполняли интенсивную научную программу, состав- ленную РАН, ЕКА, китайским ЦПК, NSBRI (США) и другими российскими и иностранными партнерами, которая включала более 100 исследовательских проектов. Основной целью проекта являлось изучение взаимодействия в контуре «человек - окружающая среда» и получение экспериментальных данных о состоянии здоровья и работоспособности человека, находящегося в условиях изоляции в герметично замкнутом пространстве ограниченного объема при моделировании основных отличий и ограничений, присущих автономному марсианскому полету.

Опыт экспериментальной работы, заинтересованность иностранных партнеров и понимание взаимных преимуществ от объединения усилий при проведении комплексных исследований позволили нам сформировать концепцию создания на базе ИМБП Международного центра по разработке технологий медицинского обеспечения межпланетных полетов. Такой подход встречает общую поддержку, и мы подтверждаем его целесообразность конкретными делами. В настоящее время институтом в тесном сотрудничестве с подразделением HRP (Human Research Program) NASA, при участии широкой международной кооперации, представленной сегодня ЕKA, а также космическими агентствами Германии, Франции, рядом университетов и организаций Бельгии, Италии, Чехии, Беларуси, реализуется проект «Сириус», предусматривающий серию экспериментов по изоляции продолжительностью до года и более и направленный на решение пси- 
хологических и физиологических проблем перспективных межпланетных полетов. К участию в программе проявляют интерес специалисты космических агентств ОАЭ, Индии, рассматриваются заявки на эксперименты, поступившие из Японии и Австралии. Одной из важных задач в эксперименте «Сириус» является исследование влияния гендерного фактора на взаимоотношения и взаимодействие в экипаже.

- Гиава Космического государства Асгардия И. Р. Аџурбейли в 2019 году объявии главной целью государства рождение ребенка в космосе. Гомландская компания SpaceBorn United проводит исследования в этой области и создает научно-техническую базу дия обеспечения воспроизводства человечества в космосе (https://www. vesvks.ru/vks/article/kompaniya-spaceborn-unitedplaniruemye-missii-po-z-16468). Существуеm версия, что подобные закрытые эксперименты могуm проводиться в Китае. Ведутся иии планируются исследования по репродукции человека в космосе Инстимутом медико-биологических проблем? Известно, что эмбриологические эксперименты велись с репродукцией мух дрозофип и крыс. Каковы результаmы и выводы этих экспериментов?

\section{«Рождение человека в космосе -} это серьезная фундаментальная и научно-прикладная задача, которую можкно и нужнно решить во имя мечты человечества об освоении других миров».

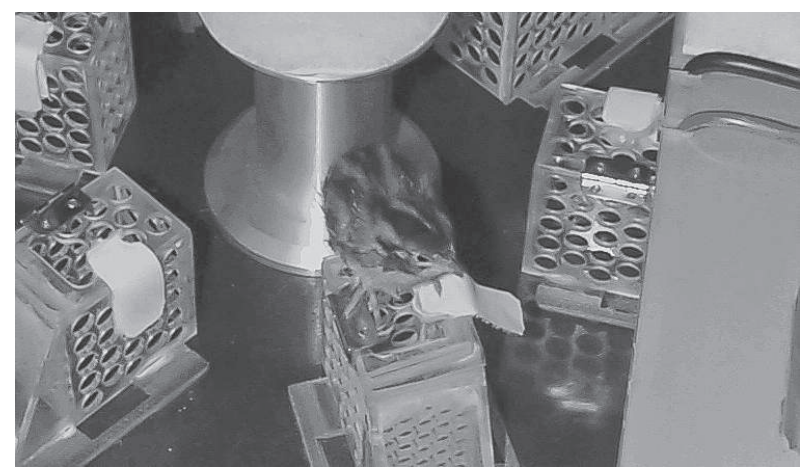

- Рождение живых организмов в условиях невесомости наблюдалось неоднократно. Это и плодовые мушки дрозофилы, и птенцы перепела. Однако возможность безопасного развития и рождения человека в условиях космического полета оценить пока трудно. На большинство вопросов пока нет исчерпывающих ответов. Например, как происходит созревание половых клеток - как мужских, так и женских, сам процесс оплодотворения и имплантации. Допу- стим, на начальных этапах (это, конечно, не решение проблемы репродукции человечества в космосе) возможные риски можно попытаться обойти применением процедуры ЭКО, предварительно получив здоровые клетки в земных условиях. Как протекает беременность в условиях космического полета? В экспериментах на крысах, которых мы отправляли в космос на разных этапах беременности, показано появление потомства без критичных для дальнейшего развития изменений. В то же время клеточные зародыши мышей, отправленные в космос нашими американскими коллегами, не выжили, хотя причина окончательно и не установлена. Как протекает процесс родов? Кто это видел - я имею виду специалистов не медицинского профиля, - тот поймет, насколько непросто обеспечить сопровождение родов в условиях космического полета. А как будет развиваться дальше ребенок, рожденный в этих условиях? Вопросов много. Если не сводить проблему к сексу в космосе и разовой пиар-акции с непредсказуемым результатом и сомнительной юридической и нравственной основой, то это серьезная фундаментальная и научно-прикладная задача, которую можно и нужно решить во имя мечты человечества об освоении других миров.

- Каковы действия экипажа в дальнем космическом полете, если один из космонавтов окажется заражен коронавцрусом ияи другой опасной инфекцией?

- Опасную инфекцию в космический полет можно только взять с собой с Земли. Поэтому в первую очередь - проведение противоэпидемических мероприятий, разрабатываемых в том числе в связи с пандемией коронавирусной инфекции. Настоятельно рекомендую соблюдать предписания врачей по этому поводу. Желаю здоровья читателям «Воздушно-космической сферы» и гражданам Асгардии. Берегите себя и своих близких!

(C) Плетнер К.В., 2020

История статьи:

Поступила в редакцию: 21.05.2020

Принята к публикации: 04.06.2020

Модератор: Гесс Л.А.

Конфликт интересов: отсутствует

Для цитирования:

Плетнер К.В. Олег Орлов: медицина на службе космической мечты // Воздушно-космическая сфера. 2020. № 2. С. 16 - 25. 